\title{
Effects of Dietary Turmeric Powder on Laying Performance and Egg Qualities in Laying Hens
}

\author{
Sang-Sul Park, Jin-Man Kim², Eun-Jib Kim², Hee-Sung Kim³, Byoung-Ki An and Chang-Won Kang ${ }^{\dagger}$ \\ Department of Animal Science and Environment, Konkuk University, Seoul 143-701, Korea \\ ${ }^{1}$ Department of Food Science and Biotechnology of Animal Resources, Konkuk University, Seoul 143-701, Korea \\ ${ }^{2}$ Division of Animal Husbandry, Cheonan Yonam College, Chungnam 331-709, Korea \\ ${ }^{3}$ Seoulfeed, Co. Ltd., Incheon 405-310, Korea
}

\begin{abstract}
This experiment was conducted to investigate the dietary effects of turmeric powder (TP) on laying performances, egg qualities and its transfer into eggs. A total of two hundred, 60-wk-old, Lohmann Brown layers were divided into 4 groups, placed in to 5 replicates per group (10 layers each) and fed each one of four diets containing $0 \%$ TP (control), $0.10,0.25$ or $0.50 \% \mathrm{TP}$, respectively, for 7 wks. Egg production in the all groups fed diets containing TP were significantly higher than that in control $(P<0.05)$. No differences in feed intakes, egg and eggshell qualities were observed among the treatments, but Roche color fan number (yolk color) in group fed diet with $0.5 \%$ TP was significantly higher than in control $(P<0.05)$. In the groups fed diets containing TP, Haugh units after $2 \mathrm{wk}$ of storage were significantly higher than that of control $(P<0.05)$. The curcumin content of egg yolk in the groups fed diet containing $0.50 \%$ TP was significantly higher than those in the other groups $(P<0.05)$. The cholesterol levels of egg yolk were not influenced by dietary TP. It was concluded that dietary TP was effective in improving laying performance and internal egg qualities. TP can be also used as a feed additive for the production of value-enhanced eggs with increased yolk color and curcumin content.
\end{abstract}

(Key words : turmeric powder, curcumin content, Haugh unit, egg yolk color, laying hens)

\section{INTRODUCTION}

Curcumin, a natural yellow pigment, obtained from the rhizomes of Curcuma longa L., is a major component of turmeric and is commonly used as a spice and food-coloring agent (Govindarajan, 1980). Turmeric, which belongs to a group of aromatic spices, has been originally used as a food additive in curries to improve the storage condition, palatability and preservation of foods (Jayaprakasha et al., 2005). As added to various food preparations, turmeric preserves their freshness and imparts a characteristic flavor.

Sharma et al. (2005) suggested that curcumin has been recognized for its broad spectrum of biological activities including diverse antioxidant and anticancer properties following oral or topical administration. Moreover, many reports showed that curcumin had anti-inflammatory property and lowering effects of lipid and cholesterol in the rats (Lantz et al., 2005). It also exhibits antioxidant property due to the presence of phenolic substances (Govindarajan, 1980). Phenolic compounds act as antioxidant with mechanisms involving both free radical scavenging and metal chelation. They have ideal structural chemistry for free radical-scavenging activities, and have been shown to be more effective antioxidant in vitro than vitamins $\mathrm{E}$ and $\mathrm{C}$ on a molar basis (Toda et al., 1985).

Chicken eggs are considered to be a good source of high quality protein and healthful compounds, such as caroteinoids. We found that lutein content of egg yolk can be further increased by adding layer diet with chlorella powder enriched with lutein (Jeon et al., 2012). Thus, phytochemicals enrichment of chicken eggs will represent a beneficial contribution to human diet. The object of this study was to investigate the dietary effects of the turmeric powder on laying performances, egg qualities, characteristic of eggs during storage and its transfer into eggs.

\section{MATERIALS AND METHODS}

\section{Animals and Experimental Design}

Turmeric powder (TP) used in this study was provided by Easy Bio System, Inc. (Seoul, Korea). The chemical composi-

${ }^{\dagger}$ To whom correspondence should be addressed : kkucwkang@empal.com 
tion of TP was as following; carbohydrate, $69.4 \%$; crude protein, $6.3 \%$; ether extract, $5.1 \%$; moisture, $13.1 \%$; minerals, $3.5 \%$ and curcumin, $2 \%$. A total of two hundred 60 -wk Lohmann brown layers were randomly divided into 4 treatments with 5 replicates of 10 birds per treatment in wire cage. The layers were fed one of following four diets containing $0,0.1$, 0.25 or $0.5 \% \mathrm{TP}$, respectively, for $7 \mathrm{wks}$ (Table 1 ). The experimental diets were formulated to meet the nutrient requirements of NRC (1994). Turmeric powder was substituted at the expense of corn at $0.10,0.25$ or $0.50 \%$ levels on air-dry basis. The layers had a 1 wk adaptation period prior to the experiment. The experimental diets were provided ad libitum and water was allowed to access freely. A room temperature of $22 \pm 3^{\circ} \mathrm{C}$ and a photoperiod of $16 / 8 \mathrm{~h}$ light/dark cycle were maintained throughout the experimental period. All animal care procedures were approved by the Institute Animal Care and Use Committee at Konkuk University.

\section{Measurements and Sampling}

The experimental diets were freshly added everyday. Egg production and egg mass (grams of egg produced per day) were determined weekly basis. Interior and exterior qualities of eggs were also tested weekly. The collected eggs were kept in storage temperature of $18^{\circ} \mathrm{C}$ during 7 or 14 days to observe the change of Haugh unit. The eggs were weighed individually and then were exposed to breaking force by using an eggshell strength tester (FHK, Fugihara, Ltd., Japan). Eggshell strength was measured as the maximum force required to fracture each egg. On breaking, the egg contents were poured into glass plate to measure the albumen height. Haugh unit values were determined using a QCM+ tester $(\mathrm{QCM}+$, Technical Service and Supplies Ltd., England). Eggshell thickness was measured with a digimatic thickness micrometer gauge (Digimatic micrometer, Mitutoyo, Japan) on a piece of shell from the equatorial region. Egg yolk color was determined by comparing with Roche egg yolk color fan (Yolk color fan, Roches, Switzerland).

At the end of experimental period, 8 birds from each group were randomly selected. The blood was drawn from wing vein using sterilized syringes and centrifuged at $1,500 \mathrm{rpm}$ for 10 min. The serum was used for the determination of the various blood profiles. At necropsy, the liver was immediately removed and weighed. The concentrations of total cholesterol and high
Table 1. Formular and chemical composition of the experimental diets (air-dry basis)

\begin{tabular}{|c|c|c|c|c|}
\hline Ingredients & $\begin{array}{l}\text { Con- } \\
\text { trol }\end{array}$ & $\begin{array}{c}\text { TP } \\
0.10\end{array}$ & $\begin{array}{c}\text { TP } \\
0.25\end{array}$ & $\begin{array}{c}\mathrm{TP} \\
0.50\end{array}$ \\
\hline & \multicolumn{4}{|c|}{ 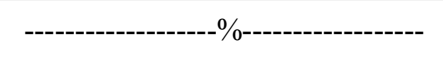 } \\
\hline Corn & 62.52 & 62.42 & 62.27 & 62.02 \\
\hline Wheat & 3.00 & 3.00 & 3.00 & 3.00 \\
\hline Lupin seed & 4.00 & 4.00 & 4.00 & 4.00 \\
\hline Soybean meal & 13.96 & 13.96 & 13.96 & 13.96 \\
\hline Rapeseed meal & 2.00 & 2.00 & 2.00 & 2.00 \\
\hline Meat meal & 3.00 & 3.00 & 3.00 & 3.00 \\
\hline Limestone & 9.51 & 9.51 & 9.51 & 9.51 \\
\hline Dicalcium phosphate & 0.55 & 0.55 & 0.55 & 0.55 \\
\hline Salt & 0.25 & 0.25 & 0.25 & 0.25 \\
\hline Tallow & 0.80 & 0.80 & 0.80 & 0.80 \\
\hline Choline-chloride $(50 \%)$ & 0.08 & 0.08 & 0.08 & 0.08 \\
\hline DL-Methionine & 0.07 & 0.07 & 0.07 & 0.07 \\
\hline Mineral mix ${ }^{1}$ & 0.10 & 0.10 & 0.10 & 0.10 \\
\hline Vitamin $\operatorname{mix}^{2}$ & 0.10 & 0.10 & 0.10 & 0.10 \\
\hline Phytase & 0.06 & 0.06 & 0.06 & 0.06 \\
\hline Turmeric powder & - & 0.10 & 0.25 & 0.50 \\
\hline Total & 100.00 & 100.00 & 100.00 & 100.00 \\
\hline
\end{tabular}

Calculated value of basal diet

$\begin{array}{lr}\text { Dry matter (\%) } & 88.80 \\ \text { Crude protein (\%) } & 16.10 \\ \text { Ether extract (\%) } & 2.95 \\ \text { Crude fiber (\%) } & 3.40 \\ \text { Crude ash (\%) } & 11.97 \\ \mathrm{Ca}(\%) & 3.86 \\ \text { Available P (\%) } & 0.50 \\ \text { Met }+ \text { Cys (\%) } & 0.65 \\ \text { TMEn }(\mathrm{kcal} / \mathrm{kg}) & 2,800\end{array}$

${ }^{1}$ Mineral mixture provided following nutrients per $\mathrm{kg}$ of diet : Fe, $48 \mathrm{mg}$; Mn, $72 \mathrm{mg}$; Cu, $5 \mathrm{mg}$; I, $1 \mathrm{mg}$; Se, $0.18 \mathrm{mg}$; Co, 0.24 mg.

${ }^{2}$ Vitamin mixture provided following nutrients per $\mathrm{kg}$ of diet : vitamin A, 12,000 IU; vitamin $\mathrm{D}_{3}, 3,000 \mathrm{IU}$; vitamin E, $21 \mathrm{IU}$; vitamin $\mathrm{K}_{3}, 2.4 \mathrm{mg}$; vitamin $\mathrm{B}_{1}, 1.2 \mathrm{mg}$; vitamin $\mathrm{B}_{2}, 4.8 \mathrm{mg}$; vitamin $\mathrm{B}_{6}, 2.4 \mathrm{mg}$; vitamin $\mathrm{B}_{12}, 0.02 \mathrm{mg}$; niacin, $15 \mathrm{mg}$; pantothenic acid, $10 \mathrm{mg}$; folic acid, $0.3 \mathrm{mg}$. 
density lipoprotein-cholesterol (HDL-C), the activities of glutamic-oxaloacetic transaminase (GOT) and glutamic-pyruvic transaminase (GPT) were estimated according to the colorimetric method using cholesterol (Cholesterol E kit, HDL-cholesterol kit, Youngdong Medical Corporation, Korea) and GOT-GPT diagnostic kit (BCS GOT-GPT assay kit, Bio Clinical System Corporation, Korea), following the manufacturer's direction.

The content of yolk cholesterol was measured according to the modified method of Lim et al. (2005). In brief, one gram of egg yolk was homogenized with $19 \mathrm{~mL}$ of Folch solution (chloroform:methanol $=2: 1, \mathrm{v} / \mathrm{v})$ using homogenizer $(5,000 \mathrm{~g}$, 5 min. AM 77 model, Nissei, Japan) for total lipid extraction (Folch et al., 1957). Lipid extracts were dissolved by absolute alcohol and saponified with $1 \mathrm{~mL}$ of $5 \% \mathrm{NaOH}$ for $1 \mathrm{~h}$ at 7 $0^{\circ} \mathrm{C}$. After cooling in room temperature, $5 \mathrm{~mL}$ of hexane was added and centrifuged and then $2 \mathrm{~mL}$ of upper layer was moved into silanized glass tube (Pyrex No., 13). The extracts were resolved with $1 \mathrm{~mL}$ of dimethylformamide and mixed with $0.2 \mathrm{~mL}$ of hexamethyldisilane and $0.1 \mathrm{~mL}$ of trimethylchlorsilane for derivatization. The turbid preparation obtained finally was mixed with $0.1 \% 5 \alpha$-cholesterol as an internal standard. Egg yolk cholesterol was measured by gas-liquid chromatography (HP 5890 Series II, Hewlett Packard 6890 series injector, Hewlett-Packard, Atlanta, USA) using $0.25 \mathrm{~mm}$ I.D. $\times 30 \mathrm{~m}$ silica capillary column (SACTM-5, Supelco Ltd., Pennsylvania, USA). The initial and terminal column temperature was programmed at $280^{\circ} \mathrm{C}$ without increased temperature. The detector was set at $300^{\circ} \mathrm{C}$.

The content of curcumin in eggs was measured by an improved HPLC method according to the method of Jayaprakasha et al. (2002). A HP 1100 system equipped with a binary pump, a photodiode array detector, and HP Chemstation soft- ware for data collection and analysis was used, and separation was carried out on a $200 \times 4.6 \mathrm{~mm}$ i.d., $5 \mu \mathrm{m}$, reversed-phase Prodigy ODS-Hypersil column. The injection volume was 20 $\mu \mathrm{L}$. A HP 1100 series detector was used for detection at a wavelength of $400 \mathrm{~nm}$. Egg yolks were stored at $-80^{\circ} \mathrm{C}$ prior to analysis. Egg yolk $1 \mathrm{~g}$ was mixed with dichloromethane 50 $\mathrm{mL}$ and reflowed for 1 hour. Water was removed by sodium sulfate anhydrous and volatilized using an evaporator and dissolved using methanol. The elution was carried out with gradient solvent systems with a flow rate of $1.0 \mathrm{~mL} / \mathrm{min}$ at ambient temperature. The mobile phase consisted of methanol, water and tetrahydrofuran $(30 / 67 / 3, v / v)$. Standard curcumin was provided by Sigma-Aldrich chemical Co.

\section{Statistical Analysis}

The main effects among treated groups were subjected to ANOVA using the general linear models procedure of SAS (2005), and significant differences were determined using Duncan's multiple range test at the level of $P<0.05$. Percentage data was transformed to arcsine percentage before square root percentages ANOVA was performed.

\section{RESULTS AND DISCUSSION}

\section{Egg Production}

The results of feed intake, egg productions, egg weight and egg mass in laying hens fed experiment diets were shown in Table 2. Feed intake was not changed by the dietary treatments, suggesting that dietary addition of TP did not affect palatability. Egg productions and egg mass in the groups fed diets with TP were significantly higher than those of control $(P<0.05)$. Egg production was the highest in the layers fed diet

Table 2. Effects of dietary turmeric powder on feed intake and egg production in laying hens ${ }^{1}$

\begin{tabular}{lcccc}
\hline \hline & Control & TP 0.10 & TP 0.25 & TP 0.50 \\
\hline Feed intake (g/day/hen) & $121.71 \pm 2.23$ & $122.62 \pm 2.21$ & $122.69 \pm 3.09$ & $122.48 \pm 1.76$ \\
Egg production (\%) & $75.95 \pm 0.78^{\mathrm{c}}$ & $81.45 \pm 0.71^{\mathrm{b}}$ & $79.20 \pm 0.55^{\mathrm{b}}$ & $83.71 \pm 0.65^{\mathrm{a}}$ \\
Egg weight (g/egg) & $66.76 \pm 0.24^{\mathrm{b}}$ & $66.07 \pm 0.35^{\mathrm{b}}$ & $66.82 \pm 0.17^{\mathrm{b}}$ & $67.55 \pm 0.18^{\mathrm{a}}$ \\
Daily egg mass & $50.70 \pm 0.55^{\mathrm{c}}$ & $53.86 \pm 0.55^{\mathrm{b}}$ & $52.95 \pm 0.36^{\mathrm{b}}$ & $56.64 \pm 0.51^{\mathrm{a}}$ \\
\hline
\end{tabular}

${ }^{1}$ Means \pm SE.

${ }^{a-c}$ Mean values in the same row having different superscripts are significantly different $(p<0.05)$. 
with $0.50 \%$ TP and the lowest in the layers fed the control diet. Egg weight in the group fed diet with $0.5 \% \mathrm{TP}$ was higher than that in the other groups. Egg mass in all groups fed diets with TP was significantly increased as compared with that in control group $(P<0.05)$. Samarasinghe et al. (2003) reported that treatments did not affect, during 4 wk feeding of $0.1,0.2$ and $0.3 \%$ turmeric or curcumin, feed intake, egg production, egg weight and egg mass. In this experiment, TP groups revealed increased laying performance. Especially, the birds at $0.5 \% \mathrm{TP}$ outperformed the others in egg production, egg weight and daily egg mass.

\section{Egg Qualities}

Egg shell strength, egg shell thickness, yolk color and Haugh unit in layers fed experimental diets were shown in Table 3. No differences in the egg shell strength, egg shell thickness and Haugh unit were observed among the treatments. Yolk color in the group fed $0.50 \% \mathrm{TP}$ was significantly higher than that in control $(P<0.05)$. Jacqueline et al. (1998) reported that yolk color depends on the diet of the hen. If layers get plenty of yelloworange plant pigments known as xanthophylls, they will be deposited in the yolk. Natural yellow-orange substances in turmeric might be added to light-colored feeds to enhance yolk color.

The change of Haugh unit in layers fed experimental diets during storage was shown in Table 3. The Haugh unit, an indicator of the most widely accepted measure of internal egg quality, tended to decrease according to the elapsed time of storage as found (Williams, 1992). Although no difference in the Haugh unit was observed among the treatments at the 7 day, the Haugh unit of group fed diet with TP was higher than that of control on the 14 day of storage $(P<0.05)$. Dietary TP in layer feed has beneficial effect on the change of Haugh unit during storage. The results of present study suggest that antioxidant properties of TP depend on the supplemented dosage. Bradley and King (2004) suggested that as an egg ages, it loses $\mathrm{CO}_{2}$ and moisture through the shell pores, causing the air cell within the egg to get larger. With this loss of $\mathrm{CO}_{2}$, the egg's $\mathrm{pH}$ becomes more basic and structural changes take place in the albumen, leading to a thinning of the albumen. Tilak et al. (2004) reported that aqueous and ethanol extracts of two major preparations of turmeric, corresponding to its use in cooking and medicine, showed significant antioxidant abilities. Sharma et al. (2005) suggested that according to the Food and Agriculture Organization of the United Nations, the appeal of turmeric as a coloring, food preservative and flavoring is global. Although the exact reason for the change of Haugh unit by feeding TP requires further investigation, including the change of mineral and moisture contents in albumen, it may be assumed that antioxidant effect of curcumin in TP became a cause of the increased Haugh unit.

\section{Blood Profiles}

The levels of blood GOT, GPT and total cholesterol were shown in Table 4. The serum total cholesterol concentration and HDL-C fractions did not significantly differ with the dietary treatment. Keshavarz (1976) reported similar results that turmeric or various levels of curcumin both in the presence and absence of dietary cholesterol did not reduce the chole-

Table 3. Effects of dietary turmeric powder on egg quality and the changes of Haugh unit during storage ${ }^{1}$

\begin{tabular}{lcccc}
\hline \hline & Control & TP 0.10 & TP 0.25 & TP 0.50 \\
\hline Egg shell strength $\left(\mathrm{kg} / \mathrm{cm}^{2}\right)$ & $3.25 \pm 0.08$ & $3.32 \pm 0.07$ & $3.26 \pm 0.06$ & $3.25 \pm 0.06$ \\
Egg shell thickness $(0.01 \mathrm{~mm})$ & $36.38 \pm 0.28$ & $36.77 \pm 0.29$ & $36.79 \pm 0.30$ & $36.94 \pm 0.35$ \\
Yolk color $(\mathrm{RCF})^{2}$ & $8.32 \pm 0.05^{\mathrm{b}}$ & $8.40 \pm 0.05^{\mathrm{ab}}$ & $8.39 \pm 0.06^{\mathrm{ab}}$ & $8.53 \pm 0.05^{\mathrm{a}}$ \\
Haugh unit & $67.02 \pm 0.75$ & $68.88 \pm 0.74$ & $69.00 \pm 0.84$ & $68.06 \pm 0.89$ \\
\hline Change of Haugh unit during storage & & & & \\
7 day & $40.54 \pm 2.25$ & $43.78 \pm 2.44$ & $47.35 \pm 3.09$ & $46.74 \pm 2.04$ \\
14 day & $27.63 \pm 1.56^{\mathrm{b}}$ & $37.05 \pm 2.21^{\mathrm{a}}$ & $37.90 \pm 2.11^{\mathrm{a}}$ & $36.00 \pm 1.71^{\mathrm{a}}$ \\
\hline
\end{tabular}

${ }^{1}$ Means \pm SE.

a,b Mean values in the same row having different superscripts are significantly different $(p<0.05)$.

2 RCF, Roche color fan. 
sterol of plasma. Asai and Miyazawa (2001) also found that no difference in plasma total cholesterol was observed among the treatments. But triacylglycerol concentration in the plasma VLDL fraction of rats fed curcuminoid was lower than that of control diet (Babu and Srinivassan, 1997; Ramireze-Tortosa et al., 1999). Levels of serum GOT and GPT were not influenced by the dietary TP. The levels of serum GOT and GPT are a reasonable indicator of liver or tissue damage in avian species (Lumeij, 1997). Studies of curcumin in animals have confirmed a lack of significant toxicity since an early report in which doses up to $5 \mathrm{~g} / \mathrm{kg}$ were administered orally to SpragueDawley rats (Wahlström and Blennow, 1978). Dietary consumption of turmeric up to $1.5 \mathrm{~g}$ per person per day was not associated with adverse effects in human (Eigner and Scholz, 1999). Ammon and Wahl (1991) reported that the other salient feature of turmeric/curcumin was that despite being consumed daily for centuries in Asian countries, it has not been shown to cause any toxicity. It can be concluded that dietary TP at $0.5 \%$ does not render laying hens any negative influence on physiological reaction and productivity.

\section{Cholesterol and Curcumin Content in Egg Yolk}

The effects of dietary TP on curcumin content and cholesterol in egg of laying hens were shown in Table 4. The levels of yolk cholesterol were not affected by the dietary treatments. Keshavarz (1976) reported similar results that turmeric or various levels of curcumin both in the presence and absence of dietary cholesterol did not reduce the levels of yolk cholesterol.

The levels of curcumin in egg yolk were increased with the increment of dietary TP. The curcumin content of egg yolk in the groups fed diets with TP was significantly higher than that in control group $(P<0.05)$. No curcumin was found in egg yolk from the layers fed control diet. The highest content of curcumin in egg yolk was obtained from the group fed diet with $0.50 \% \mathrm{TP}$. These results indicate that the curcumin in egg yolk can be increased by dietary supplementation of TP. When administered orally in a dose of $1 \mathrm{~g} / \mathrm{kg}$, curcumin was excreted in the feces accounted for about $75 \%$ of the dose while a little amount of curcumin appeared in the urine. It is unlikely that substantial concentrations of curcumin occur in the body after ingestion due to the poor absorption, rapid metabolism and excretion of curcumin (Wahlström and Brennow, 1978). It has been reported that $2.71 \sim 5.18 \%$ curcuminoids are presented in commercially available TP (Asai and Miyazawa., 2001). Preclinical studies of oral dosing of curcumin in rats using modern high pressure liquid chromatography (HPLC) techniques demonstrate small amounts of curcumin in plasma with higher levels of curcumin glucuronide and curcumin sulphate in plasma (Ireson et al., 2001). Sharma et al. (2005) suggest that curcumin exhibits lower oral bioavailability in rodents and may undergo intestinal metabolism, absorbed curcumin undergoes rapid first-pass metabolism and excretion in bile.

In conclusion, our results indicate that dietary TP improves egg production and yolk color. The Haugh unit of the groups fed diets with TP was significantly higher than that of control at 14 days of storage. The curcumin was transferred to the egg yolk, reflecting dietary turmeric will be a good candidate for producing value-enhanced egg enriched with curcumin.

Table 4. Effects of dietary turmeric powder on blood profiles and the contents of curcumin and cholesterol in egg yolk ${ }^{1,2}$

\begin{tabular}{lccrr}
\hline \hline & Control & TP 0.10 & TP 0.25 & TP 0.50 \\
\hline Total cholesterol $(\mathrm{mg} / \mathrm{dL})$ & $162.28 \pm 8.39$ & $148.58 \pm 4.80$ & $157.76 \pm 17.04$ & $148.73 \pm 9.14$ \\
HDL-cholesterol $(\mathrm{mg} / \mathrm{dL})$ & $45.80 \pm 1.33$ & $41.00 \pm 1.42$ & $44.73 \pm 1.18$ & $43.18 \pm 1.89$ \\
GOT (U/dL) & $157.20 \pm 16.70$ & $180.30 \pm 5.30$ & $188.58 \pm 4.84$ & $166.45 \pm 3.42$ \\
GPT (U/dL) & $5.01 \pm 0.66$ & $4.68 \pm 0.65$ & $6.19 \pm 0.75$ & $4.94 \pm 0.41$ \\
Curcumin $(\mu \mathrm{g} / \mathrm{g}$ egg yolk) & $\mathrm{ND}^{\mathrm{c}}$ & $0.26 \pm 0.02^{\mathrm{b}}$ & $0.28 \pm 0.02^{\mathrm{b}}$ & $0.34 \pm 0.02^{\mathrm{a}}$ \\
Cholesterol $(\mathrm{mg} / \mathrm{g}$ egg yolk) & $12.38 \pm 0.27$ & $11.21 \pm 0.28$ & $11.58 \pm 0.50$ & $11.72 \pm 0.18$ \\
\hline
\end{tabular}

${ }^{1}$ HDL-cholesterol, high-density lipoprotein-cholesterol; GOT, glutamic-oxaloacetic transaminase; GPT, glutamic-pyruvic transaminase; ND, not detected.

${ }^{2}$ Means \pm SE

${ }^{\mathrm{a}-\mathrm{c}}$ Mean values in the same row having different superscripts are significantly different $(p<0.05)$. 


\section{LITERATURE CITED}

Ammon HP, Wahl MA 1991 Phamacology of Curcuma longa. Planta Medica 57:1-7.

Asai A, Miyazawa T 2001 Dietary curcuminoids prevent highfat diet-induced lipid accumulation in rat liver and epididymal adipose tissue. J Nutr 131:2932-2935.

Babu PS, Srinivasan K 1997 Hypolipidemic action of curcumin, the active principle of turmeric (Curcuma longa) in streptozotocin induced diabetic rats. Mol Cell Biochem 166:169-175.

Bradely FA, King AJ 2004 Egg basics for the consumer : packaging, storage and nutritional information. UC PEER Reviewed 8145:1-6.

Eigner D, Scholz D 1999 Ferula asa-foetida and curcuma long in traditional medical treatment and diet in Nepal. J Ethnopharmacol 67:1-6.

Folch G, Lees M, Stanley GHS 1957 A simple method for the isolation and purification of total lipids from animal tissues. J Biol Chem 226:497-509.

Govindarajan VS 1980 Turmeric-chemistry, technology and quality. Crit Rev Food Sci Nutr 12:199-301.

Ireson C, Orr S, Jones DJL, Verschoyle R, Lim CK, Luo JL, Howells L, Plummer S, Jukes R, Williams M, Steward WP, Gescher A 2001 Characterization of metabolites of the chemopreventive agent curcumin in humans and rat hepatocytes and in the rat in vivo, and evaluation of their ability to inhibit phorbol ester-induced prostaglandin $E_{2}$ production. Cancer Res 61:1058-1064.

Jacqueline PJ, Richard DM, Mather FB 1998 Egg Quality. Food and Agricultural Sciences, Univ. Florida. PS 24, 1-11.

Jayaprakasha GK, Rao LJM, Sakariah KK 2002 Improved HLPC method for the determination of curcumin, demethoxycurcumin, and bisdemethoxycurcumin. J Agri Food Chem 50:3669-3672.

Jayaprakasha GK, Rao LJM, Sakariah KK 2005 Chemistry and biological activities of $C$. longa. Trends Food Sci Tech 16:533-548.

Jeon JY, Kim KE, Im HJ, Oh ST, Lim SU, Kwon HS, Moon BH, Kim JM, An BK, Kang CW 2012 The production of lutein-enriched eggs with dietary chlorella. Kor J Food Sci Ani Resour 32:13-17.
Keshavarz K 1976 The influence of turmeric and curcumin on cholesterol concentration of eggs and tissues. Poultry Sci 55:1077-1083.

Lantz RC, Chen GJ, Solyom AM, Jolad SD, Timmermann BN 2005 The effect of turmeric extracts on inflammatory mediator production. Phytomedicine 12:445-452.

Lim KS, You SJ, An BK, Kang CW 2005 Effects of dietary garlic powder and copper on cholesterol content and quality characteristics of chicken eggs. Asian-Aust J Anim Sci 19:582-586.

Lumeij JT 1997 Avian clinical biochemistry. In: Clinical Biochemistry of Domestic Animals (ed. Kaneko JJ, Harvey JW, Bruss ML, 5th) Academic Press. pp. 857-883.

National Research Council 1994 Nutrient Requirements of Poultry, $9^{\text {th }}$ ed. National Academy Press, Washington, DC.

Ramireze-Tortosa MC, Mesa MD, Aquilera MC, Quiles JL, BarÓ L, Ramirez-Tortosa CL, Martinez-Victoria E, Gil A 1999 Oral administration of a turmeric extract inhibits LDL oxidation and has hypocholesteolemic effects in rabbits with experimental atherosclerosis. Atherosclerosis 147:371-378.

Samarasinghe K, Wenk C, Silva KFST, Gunasekera JMDM 2003 Turmeric (Curcuma longa) root powder and mannanoligosaccharides as alternatives to antibiotics in broiler chicken diets. Asian-Aust J Anim Sci 10:1495-1500.

SAS 2005 SAS User's guide. Statistical Analysis System Institute. Ver. 9.1 ed. Inc., Cary, NC.

Sharma RA, Gescher AJ, Steward WP 2005 Curcumin : The story so far. Eur J Cancer 41:1955-1968.

Tilak JC, Banerjee M, Mohan H, Devasagayam TP 2004 Antioxidant availability of turmeric in relation to its medicinal and culinary uses. Phytother Res 18:798-804.

Toda S, Miyase T, Arich H, Tanizawa H, Takino Y 1985 Natural antioxidants. III. Antioxidative components isolated from rhizome of Curcuma longa L. Chem Pharma Bull $33: 1725-1728$.

Wahlström B, Blennow G 1978 A study on the fate of curcumin in the rat. Acta Pharmacol Toxicol 43:86-92.

Williams KC 1992 Some factors affecting albumen quality with particular reference to Haugh unit score. World's Poult Sci J 28:5-16.

(submitted: 2011. 11. 16, revised: 2012.3.6, accepted: 2012.3. 8) 